\title{
Notícias sobre a nova classificação das identidades trans: uma análise das fontes citadas em reportagens publicadas no Brasil
}

\author{
News about the recent classification of trans identities: an analysis of the \\ sources cited in reports published in Brazil \\ Noticias sobre la nueva clasificación de las identidades trans: un análisis \\ de las fuentes citadas en reportajes publicados en Brasil
}

Tatiana Clébicar Leite $e^{1, a}$

tatiana.clebicar@gmail.com | http://orcid.org/0000-0003-1134-8793

Katia Lerner ${ }^{1, b}$

katia.lerner@icict.fiocruz.br | http://orcid.org/oooo-0003-3655-9677

${ }^{1}$ Fundação Oswaldo Cruz, Instituto de Comunicação e Informação Científica e Tecnológica em Saúde. Rio de Janeiro, RJ, Brasil.

\footnotetext{
a Mestrado em Ciências pela Fundação Oswaldo Cruz.

${ }^{\text {b }}$ Doutorado em Sociologia e Antropologia pela Universidade Federal do Rio de Janeiro.
}

\section{Resumo}

A divulgação da décima primeira edição da Classificação Estatística Internacional de Doenças e Problemas Relacionados com a Saúde (CID-11), em junho de 2018, mereceu atenção da imprensa internacional e nacional. Nessa versão, as identidades trans deixaram de ser classificadas como doença mental e foram categorizadas como incongruência de gênero no novo capítulo relacionado à saúde sexual. Considerando que práticas discursivas conformam e são conformadas por práticas sociais e que o processo de despatologização é marcado pelos conceitos de medicalização e biomedicalização, este trabalho identifica e analisa as fontes citadas na cobertura jornalística produzida no Brasil. O objetivo é entender, a partir dos atores sociais que foram selecionados, entrevistados e citados como fontes, os sentidos construídos pelos principais jornais do país sobre o tema. Observa-se que fontes institucionais do campo da saúde concorrem com outras do campo jurídico, com representantes de movimentos sociais e pessoas trans, que falam por si.

Palavras-chave: Gênero; Transgêneros; Comunicação em saúde; Jornalismo; CID-11; Medicalização. 


\begin{abstract}
The release of the eleventh edition of the International Statistical Classification of Diseases and Related Health Problems (ICD-11) in June 2018 received international and national press coverage. In this version, transgender identities are no longer described as a mental health condition. Instead, they are classified as gender incongruence in the chapter on sexual health. Considering that discursive practices conform and are conformed by social practices and that the process of despatologization is marked by the concepts of medicalization and biomedicalization, this work identifies and analyzes the sources quoted in the journalistic coverage produced in Brazil. This study, focusing on social actors quoted as sources, aims to understand the meanings constructed by the main Brazilian newspaper about this subject. It concludes that institutional sources in the health field compete with others in the legal field, with members of social movements and trans people, who speak for themselves.
\end{abstract}

Keywords: Gender; Transgenders; Health communication; Journalism; ICD-11; Medicalization.

\title{
Resumen
}

La divulgación de la undécima edición de la Clasificación Estadística Internacional de Enfermedades y Problemas relacionados con la Salud (CID-11), en junio de 2018, mereció atención de la prensa internacional y nacional. En esa revisión, las identidades trans dejaron de ser clasificadas como enfermedad mental y fueron categorizadas como incongruencia de género en el nuevo capítulo relacionado a la salud sexual. Considerando que las prácticas discursivas conforman y son conformadas por prácticas sociales y que el proceso de despatologización está marcado por los conceptos de medicalización y biomedicalización, este trabajo identifica y analiza las fuentes citadas en la cobertura periodística producida en Brasil. El objetivo es entender, a partir de los actores sociales que fueron seleccionados, oídos y citados como fuentes, los sentidos construidos por los principales diarios del país sobre el tema. Observa que fuentes institucionales del campo de la salud concurren con otras del campo jurídico, con representantes de movimientos sociales y personas trans, que hablan por sí.

Palabras clave: Género; Transgéneros; Comunicación en salud; Periodismo; CID-11; Medicalización.

INFORMAÇÕES DO ARTIGO

Este texto compõe o dossiê $\mathbf{4 0}$ anos do movimento LGBT no Brasil: comunicação, saúde e direitos humanos.

Contribuição dos autores:

Concepção e desenho do estudo: Tatiana Clébicar Leite e Katia Lerner.

Aquisição, análise ou interpretação dos dados: Tatiana Clébicar Leite e Katia Lerner.

Redação do manuscrito: Tatiana Clébicar Leite.

Revisão crítica do conteúdo intelectual: Katia Lerner.

Declaração de conflito de interesses: não há.

Fontes de financiamento: o trabalho foi realizado com bolsa de doutorado da Coordenação de Aperfeiçoamento de Pessoal de Nível Superior (Capes).

Considerações éticas: não há.

Agradecimentos/Contribuições adicionais: a docentes e discentes das disciplinas Tópicos Especiais em Gênero, Violência e Saúde, da Escola Nacional de Saúde Pública Sergio Arouca, e Estudo Dirigido: a Doença sob uma Perspectiva Socioantropológica, do Instituto de Comunicação e Informação Científica e Tecnológica em Saúde. Ministrados no primeiro semestre de 2018, os cursos foram os espaços acadêmicos em que a construção do trabalho se iniciou.

Histórico do artigo: submetido: 29 jan. 2018 | aceito: 24 maio 2019 | publicado: 28 jun. 2019.

Apresentação anterior: não houve.

Licença CC BY-NC atribuição não comercial. Com essa licença é permitido acessar, baixar (download), copiar, imprimir, compartilhar, reutilizar e distribuir os artigos, desde que para uso não comercial e com a citação da fonte, conferindo os devidos créditos de autoria e menção à Reciis. Nesses casos, nenhuma permissão é necessária por parte dos autores ou dos editores. 


\section{Introdução}

A divulgação da décima primeira edição da Classificação Estatística Internacional de Doenças e Problemas Relacionados com a Saúde (CID-11) mereceu atenção da imprensa internacional e nacional. Após 25 anos de vigência da versão anterior, a Organização Mundial da Saúde (OMS) tornou público, no dia 18 de junho de 2018, o texto com revisões e alterações. Atualizado periodicamente, o documento visa a padronizar a linguagem sobre morbidade e mortalidade sob códigos únicos em que lesões, doenças e causas de morte são descritas e categorizadas, permitindo compilações, comparações e análises estatísticas globais sobre agravos à saúde. A publicação da recente versão, a ser oficialmente adotada por seus Estados-membros a partir de $1^{\mathrm{o}}$ de janeiro de 2022, acompanhou-se da divulgação de press-release, texto informativo elaborado para subsidiar a cobertura jornalística ${ }^{1}$.

No material de divulgação para a imprensa de todo o mundo, a OMS destaca que a elaboração do trabalho durou quase uma década e considerou mais de 10 mil propostas de revisão. Além de enfatizar o formato eletrônico da publicação, a entidade chamou a atenção para mudanças de conteúdo, como alterações nos códigos relativos à resistência microbiana e fluxos de trabalho inseguros, e mencionou novos capítulos: um deles sobre a medicina tradicional e outro sobre saúde sexual. O release trata ainda da inclusão do transtorno dos jogos eletrônicos na seção relacionada a adicções do capítulo dedicado à saúde mental².

Não parece trivial que, entre tantas alterações no compêndio, a entidade tenha sublinhado em seu release o deslocamento da agora classificada como incongruência de gênero do capítulo que trata da saúde mental - em que era categorizada como transexualismo - para outro, inédito, relacionado à saúde sexual. Trata-se de indício da proeminência que as questões de gênero alcançaram nas sociedades contemporâneas e de um movimento em direção à despatologização da transgeneridade, reivindicação de parcela significativa da população trans. Como relatado por Bento e Pelúcio ${ }^{3}$, diante da perspectiva de revisão da CID pela OMS e também do Manual Diagnóstico e Estatístico de Transtornos Mentais pela Associação Americana de Psiquiatria (DSM/APA, na sigla em inglês), grupos trans se organizaram em campanhas internacionais como a 'Pare a patologização' a fim de pleitear a retirada da transexualidade das listas de transtornos mentais dessas entidades. As autoras advogam que a patologização das práticas eróticas e de gênero conservam falácias científicas construídas e naturalizadas como verdades.

Segundo Butler ${ }^{4}$, porém, a despatologização das transexualidades envolve um debate complexo e paradoxal. Ela aponta a necessidade de oposição à classificação de transtorno mental, mas reconhece que o diagnóstico ainda assegura em sociedades como a norte-americana, onde o sistema de saúde não é universal, a viabilidade econômica para que pessoas trans tenham acesso a procedimentos médicocirúrgicos que viabilizem suas identidades de gênero. Mirando-se o contexto brasileiro, observa-se que antagonismo semelhante se manifesta. Embora o Conselho Federal de Psicologia (CFP) 5 tenha antecipado em aproximadamente um semestre a compreensão de que a transexualidade seja uma, entre outras, autodeterminação de gênero e, portanto, impassível de tratamento psicológico, ainda vigoram - e vigorarão até que a nova publicação passe a valer - os códigos da CID-10 para acesso de pessoas trans aos procedimentos ambulatoriais e hospitalares relativos à transição de gênero. Almeida e Murta ${ }^{6}$ discutem $^{2}$ a despatologização das vivências trans no país e defendem que esse processo se dê sem comprometer a atenção integral à saúde dessas populações. Para os autores, a simples retirada das identidades trans do rol de doenças pode acentuar a exclusão dessas pessoas do Sistema Único de Saúde (SUS). Eles afirmam que o necessário processo de despatologização precisa ser conjugado com a manutenção e ampliação do acesso desse público aos serviços ofertados.

O debate pode ser compreendido com mais profundidade ao se levar em conta que se insere no contexto de dois processos amplos e interligados: a medicalização ${ }^{7}$ e, mais recentemente, a biomedicalização ${ }^{8}$. Cunhados como conceitos, são utilizados por autores para analisar, com nuances e sob críticas, regimes 
em que saberes médicos - não necessariamente usados apenas por esses profissionais de saúde - orientam práticas individuais e coletivas. Em muitos trabalhos, a transexualidade é citada como exemplo para se reafirmar ou criticar a medicalização.

Tomando como pressuposto a ideia de que práticas discursivas conformam e são conformadas por práticas sociais ${ }^{9}$, este trabalho elege como objeto a cobertura jornalística produzida no Brasil sobre a alteração das identidades trans na CID-11 e tem como objetivo identificar e analisar as fontes citadas nas reportagens a fim de entender os sentidos construídos pelos principais jornais do país sobre o tema. Considera-se que sexo e gênero são construtos sociai ${ }^{10}$ e seus sentidos estão em permanente disputa simbólica ${ }^{11}$. O campo jornalístico, heterônomo, sujeito a diferentes formas e graus de pressão e conformado pela ação dos jornalistas e pelos interesses do público, opera como instância organizadora e produtora de sentidos ${ }^{12}$.

\section{Gênero, patologização e (bio)medicalização}

Entender de que forma conceitos como patologização, medicalização e biomedicalização passaram a orbitar as questões de gênero é um exercício útil para estudar dispositivos acionados nas disputas pela construção de sentidos sobre as identidades trans. Segundo Zorzanelli, Ortega e Bezerra, "o centro da questão da medicalização tem girado menos em torno da definição de doença, e mais daquela de pathos - de um estado cujas características passam a ser reconhecidas pela medicina, pelos pacientes e pela cultura como alvo legítimo de intervenção médica, terapêutica, profilática ou restauradora. Rugas, calvície e baixa estatura, por exemplo, não são doenças, mas constituem alvos correntes da ação médica, como enfatiza Conrad. Assim, o rótulo de doença é uma das formas, mas não a única, pela qual a medicalização tem lugar. O diagnóstico é um facilitador, mas não a condição exclusiva de seu exercício. Mais do que a criação de categorias, a medicalização envolveria a transformação do pathos em experiências medicamente descritas e manejadas" ${ }^{13}$.

Na segunda metade do século XIX, a inclusão de comportamentos desviantes, como a homossexualidade, num rol de categorias diagnósticas é um exemplo dessa medicalização com foco nas condutas privadas e na responsabilidade individual sobre elas. O que até então era considerado como libertinagem ou deliberada delinquência, penitenciada com fogo no século anterior pela gravidade do pecado que seria, torna-se objeto da psiquiatria, passível, portanto, de cura e tratamento"14. A noção de "inversão sexual" descrita pelos médicos ajudou a criar uma nova identidade para seus pacientes. Essa autoconsciência reformulou a maneira como sua condição era encarada por eles próprios e pelo conjunto da sociedade, ainda que posteriormente tenha contribuído para a opressão social desse grupo ${ }^{15}$.

Reconstruindo historicamente movimentos que resultaram no modelo de saúde ocidental, a socióloga australiana Deborah Lupton analisou regimes sanitários que vigoraram nos últimos trezentos anos ${ }^{16}$. A partir de Foucault, ela reitera o papel decisivo do olhar normalizador das instituições médicas na regulação social. A crença na racionalidade e na necessidade de controle no século XIX exacerbou os esforços por uma sociedade ordenada e produtiva. A remoção forçada de famílias e a vacinação compulsória contra a varíola são exemplos dessas estratégias que recaíam mais duramente sobre as populações pobres, operárias e imigrantes. Há uma associação entre depravação moral e física que ampara a obsessão com a higiene das entranhas, incluindo os órgãos sexuais. Isso supunha a normalização das experiências sexuais e a definição do que seriam comportamentos e práticas normais e desviantes. A família permanecia o alvo prioritário das ações sanitárias educativas que visavam à ordenação da sexualidade.

Apesar da descoberta dos agentes microbianos, que ao final do século XIX deixou em segundo plano determinantes sociais que contribuíam para o adoecimento, a vida sexual continuava no foco das ações sanitárias. Na Europa e na América, ganhava força a vigilância sobre a alimentação, a prática de exercícios e a educação de crianças e adolescentes. Lupton mostra como a escola se torna um lugar onde se aprende também a domar os impulsos, sendo ofertada uma educação que mirava a preservação da modéstia das 
meninas e o controle dos desejos dos meninos. A moralização das relações de gênero desde a infância traduzia o raciocínio que passava a ganhar força e marcaria boa parte do século XX: comportamento e estilo de vida estavam diretamente associados a uma gama de doenças. Uma vida regrada e equilibrada preveniria inconvenientes e garantiria uma vida longeva. Segundo Lupton, a ênfase na educação em saúde sofreu um deslocamento para promoção da saúde a partir de 1970.

Nesta época, o termo medicalização adquire maior potência nas Ciências Sociais e Humanas. Surgido nos anos 1950 com ênfase na psiquiatria, nas décadas subsequentes ele se torna um conceito importante para o debate, no qual autores apontam a conformação da medicina como uma instituição de controle social, capaz de produzir juízos supostamente neutros e objetivos do ponto de vista moral ${ }^{17}$. Segundo Zola, nascia um novo repositório da verdade graças a um sistema cada vez mais complexo que tornava a sociedade dependente dos especialistas. Quatro aspectos concretos corroboram essa tese: o alargamento do que é considerado relevante para a boa prática da medicina e, na contramão, o alargamento do que é considerado relevante pela medicina para boas práticas de vida; o controle de alguns procedimentos técnicos e o acesso quase absoluto a alguns temas tabus. Tema que reúne essas características, aponta o autor, é a mudança de sexo, exemplo que ilustra o resultado do "potencial da medicina quanto do desejo da sociedade de que a medicina use esse potencial" ${ }^{17}$.

O sociólogo americano Peter Conrad chama a atenção para o fato de que o conceito de medicalização está longe da neutralidade e tende a ser usado criticamente diante do controle social exercido pela medicina ${ }^{18}$. Em colaboração com Schneider, ele estudou comportamentos desviantes que deixaram o espectro pecaminoso ou criminal e foram incorporados ao rol de doenças passíveis de cura ou controle pela medicina ${ }^{19}$. Desde 1975, quando estudou o transtorno do déficit de atenção e hiperatividade em crianças (TDHA), esteve preocupado com as definições do termo. Naquele primeiro momento, ele enfatizava o vínculo com a jurisdição da profissão médica. Revendo seu próprio trabalho e o de outros autores como Zola, Conrad percebeu que em certos casos, porém, a profissão médica não está diretamente envolvida. Sua percepção o levou a alargar a compreensão do fenômeno social e a trazer como exemplo concreto a experiência trans. "A medicalização consiste em definir um problema em termos médicos, usar a linguagem médica para descrever um problema, adotar uma estrutura médica para entender um problema ou usar uma intervenção médica para ‘tratá-lo'. Este é um processo sociocultural que pode ou não envolver a profissão médica, levar ao controle social médico ou tratamento médico, ou ser o resultado da expansão intencional da profissão médica. A medicalização ocorre quando uma estrutura ou definição médica foi aplicada para entender ou gerenciar um problema; isso é tão verdadeiro para a epilepsia quanto para a 'disforia de gênero' (transexualismo)”18.

Com o intuito de problematizar o conceito, é preciso incorporar parte das críticas à predominância $\mathrm{e}$ ao alcance da medicalização na vida cotidiana. Uma das contribuições mais contundentes é a que aponta para o excessivo construcionismo social. Bury mostra, por exemplo, que a categoria disforia de gênero não é menos medicalizada do que transexualismo ${ }^{20}$. Conrad discorda, porém, da crítica de que os pesquisadores que utilizam o conceito de medicalização estejam mais interessados no processo que tornou uma questão um problema médico do que propriamente na etiologia médica da condição ${ }^{18}$. Para reafirmar seu argumento, ele enfatiza que a medicalização ocorreu tanto para comportamentos tidos como desviantes (como a transexualidade) quanto para processos naturais (como a infância, o envelhecimento e a menopausa).

Conrad tributa à secularização o contexto que favoreceu o florescimento e o fortalecimento da medicalização. Suicídio, homossexualidade e infertilidade são exemplos que o autor recupera para mostrar esse deslocamento do plano teológico para o médico. Isso não significa que certa moral parelha com a religiosa não esteja por trás de pressupostos da jurisdição médica ou mesmo que haja uma interpenetração de medicina e religião, como no caso dos adventistas ou dos católicos que recorrem a santos médicos. O sociólogo faz uma distinção entre a questão moral da saúde e a da saúde moral, com desdobramentos conceituais: "A medicalização propõe causas e intervenções biomédicas; a saudização propõe causas e intervenções comportamentais e de estilo de vida. Uma transforma a moral em medicina, a outra transforma saúde em moral”18. 
Outro fator que contribuiu para o processo de medicalização foi a estruturação e o monopólio da profissão médica $^{17}$. Atos e procedimentos restritos por força de lei aos médicos produziram efeitos recíprocos na forma com que esses profissionais orientam suas práticas. O controle social da medicina está fortemente associado ao domínio de tecnologias que incluem medicamentos, técnicas cirúrgicas e diagnósticas. Novamente, a transexualidade é mencionada como exemplo de medicalização: da interação com novas tecnologias depende o 'tratamento' hormonal e cirúrgico da transexualidade. Isso nos permite ponderar em que medida a medicalização da transexualidade está condicionada a avanços tecnológicos ou em que medida avanços tecnológicos estão condicionados à compreensão medicalizada da transexualidade. Dito de outro modo, as inovações técnicas alimentam o desejo da sociedade/indivíduos trans ou o desejo da sociedade/indivíduos trans motiva as inovações técnicas? O próprio Conrad responde à questão, indicando que a medicalização é um processo interativo no qual os médicos dividem posições e papéis com seus interlocutores ${ }^{18}$.

Ao mesmo tempo em que algumas experiências são medicalizadas, outras passam pelo processo inverso de desmedicalização. Conrad diferencia, porém, a desmedicalização da desprofissionalização, isto é, situações em que o médico é substituído por outros profissionais de saúde. Ele toma o parto como exemplo. Depois de um ciclo de mais de um século em que parteiras perderam a preponderância na condução dos nascimentos para obstetras, há um movimento de retorno à esfera doméstica com enfermeiras obstetrizes. Contudo, o autor afirma, o parto continua sendo um evento acompanhado por equipas médicas e que respeita protocolos definidos por instâncias médicas. Conrad cita como exemplo clássico de desmedicalização na sociedade americana a homossexualidade ${ }^{18}$. O autor lembra que a retirada do termo da DSM, em 1973, atendeu a protestos por liberdade sexual. Ressalta que, apesar de a epidemia de Aids ter contribuído para uma abordagem medicalizada dessa condição nos anos 1980, já o fez em bases simbólicas diferentes. Neste ponto, é preciso refinar os conceitos que podem ter sido prejudicados pela tradução literal. A saída da DSM parece ter mais o sentido de despatologização do que propriamente o de desmedicalização, se levarmos em conta que uma parcela considerável de homens que fazem sexo com outros homens passa por uma série de experiências medicalizadas (testes de sorologia recorrentes e uso de métodos de prevenção a infecções sexualmente transmissíveis, incluindo medicações pré e pós exposição a vírus). Conrad chama a atenção para a necessidade de a medicalização ser estudada simultaneamente com a desmedicalização.

À emergência do termo medicalização corresponderia, contraditoriamente, um declínio do domínio profissional dos médicos. Furedi ${ }^{21}$ observa a celebração da saúde como valor da sociedade ocidental e a expansão dos limites da medicina. Os gastos com saúde têm aumentado à medida que as definições das doenças se alargam. Os estudos sobre a medicalização se ocupam da crítica ao poder médico, particularmente, sobre corpos que não se enquadravam nas normas vigentes. Para o autor, os interesses profissionais dos médicos não explicam na totalidade as correntes culturais a que a medicalização se vincula. Segundo ele, a tese é potente, mas apresenta uma limitação. Seu mérito reside na capacidade de "chamar a atenção para a tendência de reinterpretar os problemas da existência como condições médicas”²1, mas pode ser questionável quando apresenta como causa a força da instituição médica.

É interessante pensar na constituição das identidades trans nessa chave. Se hoje uma parcela considerável da comunidade LGBT (Lésbicas, Gays, Bissexuais e Transsexuais) comemora a retirada da transexualidade da lista de doenças mentais da OMS, é porque essas experiências foram, no passado, reunidas sob uma mesma égide patológica que enfraqueceu a ideia de desvio moral. Refletindo sobre as incertezas manifestadas por indivíduos que não se identificam com a designação sexual que receberam ao nascer, é possível discutir o quanto "a demanda por um diagnóstico médico é alimentada por confusões sobre as percepções individuais do self. Em um momento de insegurança existencial, um diagnóstico médico tem, pelo menos, a virtude da definição"²1. A inclusão dessas experiências no capítulo dedicado à saúde sexual sob a definição de disforia de gênero levanta ainda outra questão, apontada pelo autor num tópico mais amplo. A ideia de que existe a saúde sexual demonstra a influência da medicalização dos relacionamentos íntimos. 
O domínio das técnicas e tecnologias marca um desdobramento da medicalização. A partir de meados da década de 1980, a medicina americana incorporou inovações tecnocientíficas que resultaram num processo ainda mais complexo: a biomedicalização, que "descreve os processos de medicalização multidirecionais, cada vez mais complexos e multicontidos, ampliados e reconstituídos através das novas formas sociais da biomedicina altamente tecnocientífica" . A noção de biomedicalização é fértil para a compreensão das vivências trans, justamente por envolver os conceitos de interseccionalidade, estrutura e agência, pondo em evidência, simultaneamente, mecanismos macroestruturais e novas formas de subjetividade.

O acréscimo do prefixo bio ao termo medicalização remete às possibilidades humanas e não-humanas criadas pelas novas tecnologias médicas (biologia, biotecnologia, genética etc.), que produzem e são produzidas por outros cinco movimentos emergentes: conformação da biomedicina como um setor econômico; foco na saúde, com ênfase na vigilância e nos riscos; característica tecnocientífica da biomedicina; mudanças na gestão da informação médica; e transformações de corpos e identidades. Os autores enfatizam que esses processos ocorrem ao mesmo tempo e não há, necessariamente, desconstinuidade do processo de medicalização. Ou seja, embora a biomedicalização seja um desdobramento da medicalização, não se trata de um processo evolutivo linear.

Três situações estão vinculadas a essa demanda: informatização e proliferação de bancos de dados, aplicação da biologia molecular e da genética à medicina e desenvolvimento de tecnologias médicas que permitem intervenções cada vez mais complexas em órgãos e tecidos que já podem ser biônicos ou híbridos. Dessa característica deriva outra que dialoga especialmente com a questão das identidades trans: a transformação de corpos e identidades. O corpo deixa de ser visto como imutável e torna-se passível de transformação, às vezes radical, segundo diferentes desejos e propósitos. Passa-se do controle do corpo para sua customização. Em busca de novas identidades, é possível reconfigurar em variados graus órgãos ou partes do corpo, inaugurando o que os autores chamam de subjetividades biomedicalizadas, negociadas de forma heterogênea ${ }^{8}$.

\section{A cobertura jornalística da CID-11 no Brasil}

O quadro teórico descrito provocou a reflexão sobre o lançamento da CID-11, um marco importante na construção das identidades trans. Considerando, como foi apontado na literatura, que os processos de medicalização e biomedicalização, a despeito de sua forte relação com os saberes médicos, são apropriados e fortalecidos por distintos grupos sociais, parece estratégico compreender como esse acontecimento foi noticiado pelos meios de comunicação. Isso se mostra particularmente relevante devido ao lugar que o jornalismo ocupa em nossas sociedades contemporâneas, nas quais, mesmo num cenário de disputas com novas mídias, ainda goza de inegável poder simbólico. Este trabalho tem como pressuposto a ideia de que o jornalismo é construtor de sentidos, o que pode ser particularmente percebido ao se colocarem sob análise as estratégias discursivas adotadas, que contemplam diferentes elementos: a construção textual, com o uso de certas palavras em detrimento de outras, os modos de endereçamento, a convocação de determinados atores como fontes, por exemplo. Aqui, optou-se por privilegiar as fontes citadas nos textos jornalísticos que trataram da divulgação do novo entendimento sobre o que é ser trans por se constituírem elemento crucial dentro da lógica da construção da notícia, capazes de indicar sentidos em disputa na produção jornalística. A escolha das fontes expressa a forma como o debate vem sendo tratado na sociedade brasileira e, principalmente, o modo como o jornalismo produz sentidos sobre ele. Assim, a abordagem para se compreender os sentidos relacionados às identidades trans por ocasião da mudança na CID-11 privilegiará os enunciadores (quem disse) e não os enunciados (o que se disse), ainda que esses últimos tenham sido mencionados de modo a localizar o debate e auxiliar na compreensão e qualificação das fontes. O objetivo é entender, a partir dos atores sociais que foram escolhidos, ouvidos e citados como fontes, sentidos postos em circulação nos textos, tendo especial atenção ao modo como o tema da (bio)medicalização aparece. 
Os principais veículos de comunicação publicaram notícias com base em declarações citadas direta ou indiretamente. É parte da lógica da produção jornalística o contato com as fontes, "instituições ou personagens que testemunham ou participam de eventos de interesse público"22. Essa definição básica ajuda a caracterizá-las. Chaparro evidencia o poder simbólico de que gozam: além de terem algo a dizer, as fontes jornalísticas são produtoras de ações sociais, atos e falas noticiáveis ${ }^{23}$. $\mathrm{O}$ autor argumenta ainda que atualmente se destacam as fontes performativas, capazes de gerar conteúdos valorizados pelo jornalismo e compartilhar saberes e experiências. Ao estudar a relação entre jornalistas e fontes, Silva observou que o processo de midiatização por que passa a sociedade contemporânea, em que as lógicas da cultura midiática reconfiguram as mais variadas práticas sociais ${ }^{24,25}$, influencia a disposição das fontes e tensiona a categoria profissional dos jornalistas, que "ora quer se apresentar como um fiscalizador da sociedade, ora atua no sentido de conservar e reproduzir os valores dos grupos dominantes” ${ }^{\prime 2}$. No processo de construção da notícia, a escolha das fontes a serem entrevistadas e citadas é um fator relevante num campo onde vigoram relações de poder.

Metodologicamente, adotou-se o primeiro nível de análise da perspectiva de Mouillaud $^{27}$, que observou que as fontes conservam índices de exterioridade dos enunciados ao estudar o sistema de citações. Para entender 'se' e 'como' os sentidos em circulação a respeito das identidades trans na CID-11 são atravessados pelas lógicas da medicalização e da biomedicalização, realizou-se um levantamento dos textos que abordaram o tema. Recorreu-se aos cinco jornais de maior circulação no país à época, de acordo com o Instituto Verificador de Comunicação (IVC), que audita os dados referentes à circulação impressa e eletrônica de jornais, revistas e websites. São eles: Folha de S.Paulo (SP), com média de 285.334 exemplares impressos e digitais; O Globo (RJ), com 243.404; Super Notícia (MG), com 204.715; O Estado de S.Paulo (SP), com 203.272; e Zero Hora (RS), com 181.129. Como os veículos mais expressivos estão circunscritos às regiões Sudeste e Sul, tentou-se um panorama mais abrangente dos jornais brasileiros, sendo incluídos outros dois títulos: Correio Braziliense (DF), que ocupa a sétima posição no ranking da circulação com 44.920 exemplares impressos e digitais, e A Tarde (BA), com 30.107, em nono lugar. Nenhum jornal do Norte aparece na lista dos dez maiores jornais do Brasil ${ }^{28}$.

O descritor 'classificação internacional doença' foi inserido nas ferramentas de busca dos sites das publicações. Coletaram-se as reportagens digitais publicadas entre 18 de junho de 2018, data do lançamento da CID-11, e o dia 30 do mesmo mês. A opção por esse recorte temporal visava a acompanhar possíveis desdobramentos editorais a partir do marco factual. Um recurso produtivo do jornalismo é a suíte (sequência, na tradução do francês suite), que se refere a matérias que abordam ou aprofundam em edições subsequentes a reportagem original.

Com base nesses critérios, foram recuperados 13 textos. Dois foram desconsiderados pois não abordavam a questão trans, focando no potencial comportamento compulsivo de jogadores de videogame. Resultaram 11 textos. Zero Hora apresentou o maior número de matérias: cinco. Os textos foram publicados nas editorias de Saúde, Comportamento e Opinião. O Globo publicou três reportagens na editoria Sociedade, onde as notícias relacionadas a saúde, ciências e educação são alocadas. Correio Braziliense publicou um texto na editoria Brasil. Folha de S.Paulo e O Estado de S.Paulo trouxeram um texto cada, ambos publicados em suas respectivas editorias de saúde. Os resultados estão listados compilados no Quadro 1. 
Quadro 1 - Notícias sobre identidades trans na CID-11 em jornais brasileiros

\begin{tabular}{|c|c|c|c|}
\hline Dia & Jornal & Título & Fontes citadas (em ordem alfabética) \\
\hline 18 & $\begin{array}{l}\text { Folha de } \\
\text { S.Paulo }\end{array}$ & $\begin{array}{l}\text { OMS tira transexualidade de nova versão } \\
\text { de lista de doenças mentais }{ }^{29}\end{array}$ & DSM/APA; OMS \\
\hline 18 & O Globo & $\begin{array}{l}\text { Transexualidade sai da categoria de } \\
\text { transtornos mentais da } \mathrm{OMS}^{30}\end{array}$ & $\begin{array}{l}\text { Bruna Benevides, militar trans; OMS; } \\
\text { Shekhar Saxena, diretor do departamento de } \\
\text { saúde mental e abuso de substâncias da OMS }\end{array}$ \\
\hline 18 & $\begin{array}{l}\text { O Estado de } \\
\text { S.Paulo }\end{array}$ & $\begin{array}{l}\text { OMS classifica vício em videogame como } \\
\text { distúrbio de saúde mental }{ }^{31}\end{array}$ & 'Estudiosos' (sobre transexualidade) \\
\hline 18 & Zero Hora & $\begin{array}{l}\text { Transexualidade é retirada pela OMS da } \\
\text { lista de doenças mentais }{ }^{32}\end{array}$ & OMS \\
\hline 19 & Zero Hora & $\begin{array}{l}\text { Mudança de classificação da } \\
\text { transexualidade pela OMS deve ter pouco } \\
\text { impacto no Brasil, opina especialista }{ }^{33}\end{array}$ & $\begin{array}{l}\text { APA; Maria Inês Lobato, psiquiatra, } \\
\text { coordenadora do Programa de Identidade } \\
\text { de Gênero do Hospital de Clínicas de Porto } \\
\text { Alegre; OMS }\end{array}$ \\
\hline 24 & O Globo & $\begin{array}{l}\text { Nova lista de doenças da OMS traz } \\
\text { esperança para transexuais expulsas das } \\
\text { Forças Armadas }^{34}\end{array}$ & $\begin{array}{l}\text { Bruna Benevides, segundo-sargento da } \\
\text { Marinha trans; Casa Branca; Donald Trump; } \\
\text { Éryka Fayson, ex-fuzileira naval trans; FAB; } \\
\text { junta médica da Aeronáutica; Leandro Liess, } \\
\text { endocrinologista; Maria Luiza da Silva, militar } \\
\text { trans; Marinha; Max Teleca, advogado; } \\
\text { Ministério Público Federal; OMS; Renato } \\
\text { Machado, procurador regional dos Direitos do } \\
\text { Cidadão; Exército; Tribunal Regional Federal } \\
\text { da 2a região }\end{array}$ \\
\hline 25 & Zero Hora & $\begin{array}{l}\text { Ainda hoje encontramos grupos que } \\
\text { defendem terapias conversivas, como a } \\
\text { 'cura gay'35 }\end{array}$ & OMS; CFP \\
\hline 27 & Zero Hora & $\begin{array}{l}\text { Dia do Orgulho LGBT+: data para } \\
\text { comemorar ou para reivindicar? }{ }^{36}\end{array}$ & $\begin{array}{l}\text { Filipe Roloff, líder do grupo Pride Brasil; } \\
\text { Marina Reidel, professora trans e diretora de } \\
\text { Promoção de Direitos LGBT do Ministério dos } \\
\text { Direitos Humanos; Marisa Fernandes, militante } \\
\text { feminista lésbica; Renan Quinalha, advogado, } \\
\text { ativista e professor de Direito da Universidade } \\
\text { Federal de São Paulo; Rogério Dervanoski, } \\
\text { presidente do PampaCats, equipe poliesportiva } \\
\text { LGBT de Porto Alegre }\end{array}$ \\
\hline 27 & Zero Hora & $\begin{array}{l}\text { Transexuais e travestis pedem ao STF para } \\
\text { cumprir pena em presídios femininos } \\
37\end{array}$ & $\begin{array}{l}\text { ABLGT; Ministro Luís Roberto Barroso, do STF; } \\
\text { OMS }\end{array}$ \\
\hline 28 & $\begin{array}{l}\text { Correio } \\
\text { Braziliense }\end{array}$ & $\begin{array}{l}\text { Homens transexuais buscam visibilidade } \\
\text { para novas gerações }{ }^{38}\end{array}$ & $\begin{array}{l}\text { Leonardo Peçanha, ativista e professor de } \\
\text { Educação Física; Letícia Furtado, defensora } \\
\text { pública; Luiz Montenegro, pesquisador da } \\
\text { Ensp/Fiocruz; Patrick Lima, homem trans }\end{array}$ \\
\hline 29 & O Globo & $\begin{array}{l}\text { Transexuais já podem mudar nome em } \\
\text { documentos nos cartórios de todo país }{ }^{35}\end{array}$ & $\begin{array}{l}\text { Corregedoria Nacional de Justiça; STF; Maria } \\
\text { Eduarda Aguiar, advogada trans; OMS }\end{array}$ \\
\hline
\end{tabular}

Fonte: As autoras (2019).

Embora o principal jornal de Brasília tenha omitido a questão trans na primeira matéria em que abordou o tema, no dia 18, recuperou o assunto na edição do dia 28, data em que se celebra o Orgulho LGBTQI. A matéria "Homens transexuais buscam visibilidade para novas gerações" ${ }^{8}$ de autoria atribuída à Agência Brasil, distribuidora pública de notícias, foi elaborada a partir de entrevistas feitas com um homem trans, Patrick Lima, identificado com foto, que descreveu os percalços enfrentados até o exercício pleno de sua identidade; 
um ativista e professor de Educação Física, que abordou os entraves no mercado de trabalho para esta população; uma defensora pública do Núcleo de Defesa dos Direitos Homoafetivos e Diversidade Sexual; e um pesquisador da Escola Nacional de Saúde Pública Sergio Arouca da Fundação Oswaldo Cruz (Ensp/ Fiocruz), que chamaram a atenção para o acesso aos serviços de saúde.

Citando indiretamente fontes institucionais, a Folha de S.Paulo contextualiza as mudanças na CID e enfatiza que "claras evidências científicas" subsidiaram a revisão. Chama ainda atenção para o fato de que, com a manutenção da transexualidade no rol, "dissipa-se o temor da perda de cobertura por cobertura (sic) pelos sistemas de saúde" ${ }^{29}$. O Globo logo na primeira matéria menciona juntamente com a OMS e seu diretor para saúde mental e abuso de substâncias, Shekhar Saxena, a militar reformada Bruna Benevides. Ao apresentar Bruna, cuja fotografia ilustra a notícia, o texto menciona que ela foi "afastada de seu cargo na Marinha sob justificativa de ser incapaz devido a quadro de "transexualismo"30. Essa informação merece ser registrada porque ainda na mesma semana, no domingo, edição mais valorizada pelos jornais, o assunto volta à pauta numa reportagem de página inteira sobre o afastamento de mulheres trans das Forças Armadas ${ }^{34}$. Além de Bruna, outras duas ex-militares são citadas, e uma delas, Maria Luiza Silva, aparece na matéria em três fotografias. $\mathrm{O}$ texto faz remissão à questão nos Estados Unidos e cita indiretamente o presidente norte-americano Donald Trump. São mencionadas ainda fontes médicas (uma junta da Aeronáutica e um endocrinologista) e representantes do campo jurídico. Fontes do campo jurídico foram acionadas na terceira matéria publicada no jornal carioca para repercutir da decisão do Supremo Tribunal Federal (STF) que franqueou às pessoas trans o direito de registrar o nome social em cartório ${ }^{39}$. Nessa ocasião, além do STF e da Corregedoria Nacional de Justiça (CNJ), é entrevistada e fotografada a advogada Maria Eduarda Aguiar, primeira pessoa trans a incluir o nome social nos registros da Ordem dos Advogados do Brasil. A OMS também é citada na referência feita à alteração da CID.

Zero Hora restringiu-se à OMS como fonte na primeira matéria publicada ainda em 18 de junho ${ }^{32}$. No dia seguinte, porém, o jornal gaúcho deu sequência à cobertura factual mencionando, além da entidade mundial, a APA e a psiquiatra Maria Inês Lobato, que coordena o Programa de Identidade de Gênero do Hospital de Clínicas de Porto Alegre (HCPA) ${ }^{33}$. O recurso a especialistas do contexto local é uma estratégia comumente usada para aproximar o noticiário internacional das realidades locais e já foi estudado em trabalhos que investigam como o jornalismo se vale de sistemas perito ${ }^{40}$. Nesse caso, porém, o argumento de autoridade é reforçado pela informação de que a médica "liderou no Brasil as discussões para a renovação da CID-11 nessa área"33. Uma semana depois o assunto volta a receber destaque na publicação de um artigo de opinião escrito pelo psicólogo Angelo Brandelli Costa, conselheiro do Conselho Regional de Psicologia (CRP-RS), que toma como fonte resoluções do órgão de classe e a própria OMS para reiterar a inviabilidade de terapias gêneroconversivas justamente porque homo e transexualidade são diferentes formas de expressão da natureza humana $^{35}$. Dois dias depois, antecipando o Dia do Orgulho, o jornal entrevistou cinco fontes LGBTQI (Lésbicas, Gays, Bissexuais, Travestis, Transexuais, Transgêneros, Queer e Intersexo), que avaliaram avanços e desafios dessas populações. Entre os entrevistados, estava a professora Marina Reidel, trans, diretora de Promoção de Direitos LGBT do Ministério dos Direitos Humanos ${ }^{36}$. O tema aparece em outro texto da mesma edição. A notícia de que a Associação Brasileira de Lésbicas, Gays, Bissexuais, Travestis, Transexuais e Intersexos (ABGLT) encaminhara ao STF uma ação em que pedia que a mulheres trans e travestis cumpram penas em presídios femininos incluiu menção à mudança na CID como uma conquista histórica ${ }^{37}$.

O Estado de S.Paulo optou pelo enquadramento da questão dos videogames ao noticiar a atualização da CID. Apesar disso, o jornal paulista incluiu um parágrafo destacado pelo entretítulo "Transexualidade". A alteração relativa ao tema é noticiada de forma sucinta e atribuída a fontes não identificadas: "Os estudiosos disseram que a classificação anterior levava a um estigma para pessoas transexuais, para quem há necessidade de melhorias no atendimento de saúde" ${ }^{31}$. Para a análise a ser empreendida, esse tipo de fonte não foi computado dada a sua imprecisão e inespecificidade. $\mathrm{O}$ apagamento da identidade dessas fontes sugere que o jornal toma 
para si a autoridade na enunciação, mas trata-se de um tópico a ser problematizado oportunamente. Também foram desconsideradas as sete fontes que abordaram unicamente o problema dos jogos.

Ao todo foram contabilizadas 42 fontes que mencionaram a CID-11. Classificamos esses atores nos seguintes grupos: campo da saúde (16), campo jurídico/segurança pública (12); campo político (2); pessoas trans (7); e representantes de movimentos sociais (5). Descontadas as reiterações, quase todas referentes à presença da OMS nos textos jornalísticos, registraram-se 33 diferentes atores sociais a falar sobre o tema. Algumas fontes têm uma inserção híbrida, por exemplo, a advogada trans Maria Eduarda Aguiar ou a junta médica da Aeronáutica. Nesses casos, a compreensão dos enunciados foi útil a fim de entender que sentidos sua presença nos textos ajuda a construir.

\section{A escolha das fontes e seus sentidos}

A análise das fontes selecionadas para compor as matérias sobre as mudanças da CID-11 que tratam da categorização da transexualidade fora do âmbito da saúde mental indica num primeiro nível a força que as fontes institucionais têm junto aos veículos de comunicação. Todas as onze matérias coletadas evocam a força das instituições, quer reproduzindo literalmente seus posicionamentos divulgados por meio de releases, notas ou publicações, quer apresentando como chancela de autoridade credenciais das pessoas físicas ouvidas (representantes, médicos, pesquisadores). A menção a fontes institucionais não é uma prerrogativa da cobertura de saúde ${ }^{23,26}$, tampouco do tema dos transgêneros ${ }^{41}$. Ao contrário, uma estratégia para afirmação da legitimidade do discursivo jornalístico é o espaço concedido a fontes oficiais, que podem eventualmente ser contraditas por outras.

Embora não possam ser classificadas como fontes oficiais, representantes de movimentos sociais, que apareceram quatro vezes seja na forma de pessoa jurídica (ABGLT), seja por intermédio de membros ativistas, também ajudam a conferir a ideia de legitimidade, já que falam por coletivos. Diferentemente de porta-vozes de instituições e movimentos sociais, as pessoas trans foram citadas em sete ocasiões e compõem outra categoria. Elas forneceram para os jornalistas elementos pessoais ao falarem por e de si. Uma delas, a militar Bruna Benevides, foi referida em duas matérias, a única reiteração que fugiu aos campos da saúde e do direito.

Entre as instituições, as do campo da saúde foram as mais acionadas. A OMS foi referida nove vezes, incluindo uma por meio da citação de um diretor. A APA, duas vezes; Fiocruz, CFP, HCPA foram mencionados uma vez cada. A opção por essas fontes está relacionada não apenas ao campo em que a pauta foi gestada, mas também ao enquadramento adotado nas matérias para tratar de gênero. Essa afirmação se sustenta se observarmos que logo atrás do campo da saúde é o campo jurídico que emerge como segundo principal berço das fontes institucionais: as menções a STF, Ministério Público Federal, TRF, CNJ demonstram que estão em curso disputas legais - e também simbólicas - relativas aos direitos das populações. Coube às Forças Armadas o terceiro lugar na estratificação das fontes. As fontes institucionais do campo militar foram todas citadas na matéria de O Globo, que tratou das oficiais e praças afastadas de seus postos de trabalho.

Olhadas conjuntamente, as fontes dos campos da saúde, da justiça e da segurança demonstram que a articulação entre eles, tendo a transexualidade como tópico, está relacionada à capacidade de trabalho, violência e luta por direitos. Numa sociedade sexuada e sexista, as questões de gênero são, mais do que pretexto, um dispositivo de poder. O efeito culminante da forma como opera este tipo de poder é o exercício da violência de gênero ${ }^{42}$. No caso das militares trans citadas, essa violência as alijou do trabalho, retirando delas uma esfera de realização. A normatividade cisgênera e binária reforça a vulnerabilidade em saúde de pessoas trans e de outras identidades e corpos que não se alinhem a essa norma ${ }^{43}$. Nesse sentido, é útil não perder de vista a concepção de que as produções discursivas a respeito de gênero na saúde conformam e são conformadas, numa via de mão dupla, pelas práticas sociais da própria saúde e de outros campos: "O 
único mapa seguro que guia o olhar do médico e dos membros da equipe são as verdades estabelecidas socialmente para os gêneros, portanto estamos no nível do discurso. Não existe um só átomo de neutralidade nesses códigos. Estamos diante de um poderoso discurso que tem como finalidade manter os gêneros e as práticas eróticas prisioneiras à diferença sexual”’

Nem sempre, porém, a cobertura das questões trans é assim. Em trabalho anterior, que analisou as fontes citadas em reportagens sobre o tema em um único jornal brasileiro no período de duas décadas, desde a primeira menção do termo 'transgênero', a predominância foi das fontes dos campos político e cultural, seguidas de representantes de movimentos sociais e de pessoas trans. Nesse recorte prolongado, pesquisadores das Ciências Sociais concorrem muito de perto com os do campo médico ${ }^{41}$.

Uma segunda categoria de análise foi a dos atores sociais enquanto pessoas físicas, mesmo que representando instituições. Esse grupo correspondeu a metade das fontes identificadas. A opção por fontes ‘de carne e osso' favorece a compreensão das questões envolvidas na densidade das histórias vividas e em sua complexidade cotidiana. Põe em circulação demandas e reivindicações coletivas das parcelas diretamente envolvidas mesmo quando falam apenas por si. Diante dos variados e específicos interesses de cada população integrante da sigla LGBTQI, destaque-se que representantes de movimentos sociais parecem dispor de mais legitimidade como fontes quanto maior for sua identificação com a causa abordada na matéria. Significa dizer que uma fonte trans recebe mais espaço, incluindo fotos e citações em destaque, do que uma fonte que representa o movimento, mas não oferece um testemunho pessoal. Essa observação corrobora a ideia de que o jornalismo se utiliza recorrentemente dos testemunhos como um dispositivo discursivo ${ }^{44}$. Cabe discutir se, no caso das fontes trans, sua presença nas páginas de jornal é marcada pela excepcionalidade, revelada por relatos de sofrimento e superação, ou trata-se de depoimentos revestidos de um caráter ordinário, cada vez mais frequentes nos dramas cotidianos de pessoas comuns ${ }^{45}$. Ainda não parece ser esse segundo caso. Nos textos que tratam da alteração da CID, figuram em maior número pessoas trans que compartilham um pouco de suas trajetórias do que representantes de movimentos que trazem uma visão do coletivo da população LGBT. No entanto, as fontes trans representam metade das fontes do campo da saúde e dois terços daquelas oriundas do campo jurídico e da segurança.

Considerando que este trabalho está centrado num debate sobre gênero, pareceu relevante também tomá-lo como categoria para análise. Observou-se a seguinte composição entre as 21 entrevistas: onze homens cisgêneros, seis mulheres trans (uma fonte ouvida duas vezes), três mulheres cis e um homem trans. Não chega a ser surpresa a predominância de fontes masculinas cis. É mais um sinal de seu poder simbólico. Não cabe aqui questionar sua competência em seus campos de atuação, mas de dar a visibilidade à desigualdade de representação. Possivelmente, há mais fontes masculinas porque há mais homens nas diretorias da OMS, no STF e nas instituições de pesquisa, conforme demonstram trabalhos sobre a divisão por gênero em instâncias jurídicas e científicas ${ }^{46,47}$. A clivagem por gênero permite ainda observar que essa razão se inverte quando contabilizamos as fontes trans. As mulheres trans foram citadas mais vezes do que o único homem trans que compartilhou sua história de vida. Esse dado nos remete a um debate a respeito da legitimidade de fala e visibilidade recorrente nas comunidades e grupos ativistas LGBT, cuja sigla aliás, é um exemplo: por reivindicação das mulheres, o L passou à frente do G. Ele levanta uma dúvida: novas categorias reproduzem antigas hierarquias? Convém destacar que não se pode estabelecer uma relação automática entre a identidade de gênero das fontes e o teor de seus enunciados. Para tanto, seriam necessárias outras análises. 


\section{Conclusões}

A análise das notícias sobre a revisão da CID-11 publicadas nos jornais de maior circulação no Brasil em junho de 2018 permitiu observar a predominância de fontes institucionais, principalmente do campo da saúde, o que não difere do modo de fazer já observado em outros trabalhos ${ }^{23,26}$. Além disso, se comparadas exclusivamente as fontes da saúde, majoram as fontes biomédicas, o que também foi observado de estudos anteriores ${ }^{48}$.

A OMS, produtora do fato, foi a entidade mais citada entre as 42 fontes acionadas nos onze textos analisados. Instituições do campo jurídico também foram citadas recorrentemente em matérias que contextualizavam a luta por direitos travada pelas populações trans, indicando que as disputas em torno das questões de gênero são simbólicas e concretas neste momento histórico. A valorização das fontes institucionais foi, de certo modo, ponderada pela presença de depoimentos de pessoas trans, que ocuparam a centralidade discursiva em algumas matérias ao relatarem suas vivências e percalços em busca do direito de serem o que são em todos as esferas da existência.

A despeito do movimento em direção à despatologização que a retirada das identidades trans do capítulo de saúde mental da CID significa, o assunto ainda é enquadrado pelas lentes do campo da saúde como sugere o elevado número de fontes oriundo dele. Coube majoritariamente a médicos, pesquisadores e outros atores do campo da saúde a repercussão dessa mudança. O fato de que nenhum especialista das Ciências Sociais tenha sido convocado pela imprensa a comentar os desdobramentos da categorização da incongruência de gênero no novo capítulo dedicado à saúde sexual é digno de nota, mas não chega a surpreender. As ciências médicas e biológicas tendem a predominar nos jornais brasileiros ${ }^{49}$. A repercussão da mudança junto a sociólogos e antropólogos poderia enriquecer o debate e contribuir para a construção de outros sentidos em torno das vivências trans.

Refletir sobre essas experiências - e a reinvindicação de sua despatologização - requer compreender os processos mais amplos de medicalização, desmedicalização e biomedicalização. Tais termos contêm sentidos e nuances que contribuem para o entendimento mais preciso dos fenômenos sociais. Se a patologização hoje tem um sentido de controle social, a biomedicalização, nesse caso, seria uma chave que ajuda a compreender essas vivências e legitimar a oferta de uma assistência integral às pessoas que desejam ou precisam adequar sua identidade psíquica à corporal. Considerando as experiências trans, a noção de biomedicalização parece, portanto, fecunda para o entendimento do que vivem indivíduos e grupos que ressignificam o corpo nesse início de século. Ela trata não só das relações da tecnociência com a saúde e o corpo, mas principalmente de processos contemporâneos de subjetivação e construção de identidade. O conceito lança luz sobre o que se é, o que se pode ser e o que se deseja ser.

Levando-se em conta que ojornalismo reflete e refrata - simultaneamente - sentidos que circulam no lugar e no tempo histórico em que está imerso, estudar as fontes das reportagens permitiu observar características da produção discursiva daquele contexto social. Trabalhos que investiguem os enunciados construídos e postos em circulação pelas fontes podem contribuir para uma compreensão mais aprofundada do tema. A presença de Bruna Benevides, Éryka Fayson, Maria Eduarda Aguiar, Maria Luíza da Silva, Marina Riedel e Patrick Lima, pessoas trans que conquistaram poder de produzir ações sociais, atos e falas noticiáveis como fontes, sugere que, a despeito de forças contrárias, há mudanças em curso na sociedade brasileira.

\section{Referências}

1. Duarte J. Assessoria de imprensa e relacionamento com a mídia: teoria e prática. São Paulo: Atlas, 2010. Release: história, técnica, usos e abusos; p. 51-75.

2. Organização Mundial da Saúde Brasil. OMS divulga nova classificação internacional de doenças [Internet]. Brasília: A Organização; 2018 [citado em 2018 dez. 18]. Disponível em: https://bit. $\underline{\mathrm{Iy} / 2 \mathrm{lkLCDO}}$ 
3. Bento B, Pelúcio L. Despatologização do gênero: a politização das identidades abjetas. Estud Fem [Internet]. 2012 mai-ago [citado em 2018 dez. 18];20(2):569-81. Disponível em: https://bit.ly/2Z9KhkO

4. Butler J. Desdiagnosticando o gênero. Physis [Internet]. 2009 [citado em 2018 dez. 18];19(1):95-126. Disponível em: http://www.scielo.br/scielo.php?script=sci arttext\&pid=S010373312009000100006\&lng=en.

5. $\quad$ Conselho Federal de Psicologia (BR). Resolução CFP no 1, de 29 jan. 2018. Estabelece normas de atuação para as psicólogas e os psicólogos em relação às pessoas transexuais e travestis [Internet]. Brasília: O Conselho; 2018 [citado em 2018 dez. 18]. Disponível em: https://site.cfp.org.br/wp-content/ uploads/2018/01/resolucao cfp 01 2018.pdf

6. Almeida G, Murta D. Reflexões sobre a possibilidade da despatologização da transexualidade e a necessidade da assistência integral à saúde de transexuais no Brasil. Sex Salud Soc [Internet]. 2013 [citado em 2018 dez. 18];14:380-407. Disponível em: https://bit.ly/2ZasKcu

7. Conrad P. The medicalization of society: on the transformation of human conditions into treatable disorders. Baltimore: Johns Hopkins University Press; 2007.

8. Clarke A, Shim J, Mamo L, Fosket J, Fishman, J. Biomedicalization: technoscientific Transformations of Health, Illness, and U.S. Biomedicine. Am Sociol Rev 2003;68(2):161-94.

9. Fairclough N. Discurso e mudança social. Brasília: UnB; 2001.

10. Butler J. Problemas de gênero: feminismo e subversão da identidade. Rio de Janeiro: Civilização Brasileira; 2017.

11. Bourdieu P. Os usos sociais da ciência. São Paulo: Unesp; 2004.

12. Bourdieu P. The political field, the social science field, and the journalistic field. In: Benson R; Neveu E, editors. Bourdieu and the journalistic field. Cambridge: Polity Press; 2005. p. 29-47.

13. Zorzanelli RT, Ortega F, Bezerra Junior B. Um panorama sobre as variações em torno do conceito de medicalização entre 1950-2010. Ciênc Saúde Coletiva [Internet]. 2014 [citado em 2018 dez. 18];19(6):1859-68. Disponível em: https://bit.ly/2QWHOHT

14. Foucault M. Microfísica do poder. São Paulo: Graal; 2012.

15. Hansen B. American physicians' 'discovery' of homosexuals, 1880-1900: a new diagnosis in a changing society. In: Rosenberg C, Golden J, editores. Framing disease. Studies in cultural history. New Brunswick, New Jersey: Rutgers Univeristy Press; 1977. p. 104-133.

16. Lupton D. The imperative of health: public health and the regulated body. London: Sage; 1995.

17. Zola I. Medicine as an Institution of Social Control. Soc Review 1972;20(4):487-504.

18. Conrad P. Medicalization and social control. Annu Rev Sociol. 2002;18:209-32.

19. Conrad P, Schneider J. Deviance and medicalization: from badness to sickness. Philadelphia: Temple University Press; 1980.

20. Bury M. Chronic illness as biographical disruption. Sociol Health Illn. 1982 July;4(2):167-82.

21. Furedi $F$. The end of professional dominance. Society 2006;43(6):14-18.

22. Lage N. A reportagem: teoria e técnica de entrevista e pesquisa jornalística. Rio de Janeiro: Record; 2006.

23. Chaparro C. Jornalismo na fonte. In: Dines A, Malin M, organizadores. Jornalismo brasileiro: no caminho das transformações. Brasília: Banco do Brasil; 1996. p.132-154.

24. Fausto Neto A. Fragmentos de uma analítica da midiatização. Matrizes [Internet]. 2008 [citado em 2018 dez. 18];2(1):89-105. Disponível em: https://bit.ly/2Z7aRuX

25. Rodrigues AD. Prefácio. In: Janotti Junior J, Mattos MA, Jacks N. Mediação \& Midiatização. Salvador: EDUFBA; Brasília: Compós; 2012.

26. Silva TRN. Jornalistas e fontes: uma relação em movimento. Temas, vozes e silêncios na Saúde de 0 Globo (1987-2015) [tese] Rio de Janeiro: Fundação Oswaldo Cruz; 2017.

27. Mouillaud M. O sistema de citações. In: Mouillaud M, Porto SD, organizadores. O jornal: da forma ao sentido. Brasília: Universidade de Brasília; 2012. 
28. Tiragem impressa dos maiores jornais perde 520 mil exemplares em 3 anos [Internet]. Brasília: Poder 360; 2018 [citado em 2018 dez. 18]. Disponível em: https://bit.ly/2Eu1WuE

29. OMS tira transexualidade de nova versão de lista de doenças mentais [Internet]. Folha de S.Paulo (Grupo Folha) 2018 jun. 24 [citado em 2018 dez. 18]:Equilíbrio e Saúde. Disponível em: https://bit. Iy/2M5QDLK

30. Transexualidade sai da categoria de transtornos mentais da OMS [Internet]. O Globo (Globo S/A) 2018 jun. 18 [citado em 2018 dez. 18]:Sociedade. Disponível em: https://glo.bo/2InWkEi

31. OMS classifica vício em videogame como distúrbio de saúde mental [Internet]. O Estado de S.Paulo (Grupo Folha) 2018 jun. 18 [citado em 2018 dez. 18]:Saúde. Disponível em: https://saude.estadao.com. br/noticias/geral,oms-classifica-vicio-em-videogame-como-disturbio-de-saude-mental,70002354974

32. Transexualidade é retirada pela OMS da lista de doenças mentais: nova versão da CID ainda passará por aprovação em maio de 2019. Classificação não era revista desde 1990 [Internet]. Zero Hora (Grupo RBS) 2018 jun. 18 [citado em 2018 dez. 18]:Saúde:Revisão histórica. Disponível em: https://gauchazh. clicrbs.com.br/saude/noticia/2018/06/transexualidade-e-retirada-pela-oms-da-lista-de-doencas-mentaiscjikz7owh0him01qoy5uu4pw9.html

33. Mudança de classificação da transexualidade pela OMS deve ter pouco impacto no Brasil, opina especialista [Internet]. Zero Hora (Grupo RBS) 2018 jun. 19 [citado em 2018 dez. 18]:Saúde:Contra o preconceito. Disponível em: https://bit.ly/2MMxa3P

34. Ferreira P. Nova lista de doenças da OMS traz esperança para transexuais expulsas das Forças Armadas [Internet]. O Globo (Globo S/A) 2018 jun. 24 [citado em 2018 dez. 18]:Sociedade. Disponível em: https://oglobo.globo.com/sociedade/nova-lista-de-doencas-da-oms-traz-esperanca-para-transexuaisexpulsas-das-forcas-armadas-22813739

35. Costa AB. Ainda hoje encontramos grupos que defendem terapias conversivas, como a "cura gay" [Internet]. Zero Hora (Grupo RBS) 2018 jun. 25 [citado em 2018 dez. 18]:Opinião:Curando o preconceito . Disponível em: https://gauchazh.clicrbs.com.br/opiniao/noticia/2018/06/ainda-hoje-encontramos-gruposque-defendem-terapias-conversivas-como-a-cura-gay-cjiurzxvt0jhn01qow8cp6t27.html

36. Hartmann M. Dia do Orgulho LGBT+: data para comemorar ou para reivindicar? [Internet]. Zero Hora (Grupo RBS) 2018 jun. 27 [citado em 2018 dez. 18]:Diversidade. Disponível em: https://gauchazh. clicrbs.com.br/comportamento/noticia/2018/06/dia-do-orgulho-lgbt-data-para-comemorar-ou-parareivindicar-cjixtvib70k9j01qovmqaec7g.html

37. Milman T. Transexuais e travestis pedem ao STF para cumprir pena em presídios femininos [Internet]. Zero Hora (Grupo RBS) 2018 jun. 27 [citado em 2018 dez. 18]:ABLGT. Disponível em: https://gauchazh.clicrbs.com.br/colunistas/tulio-milman/noticia/2018/06/transexuais-e-travestis-pedemao-stf-para-cumprir-pena-em-presidios-femininos-cjixc7jae0gw401pa9qyogqjp.html

38. Homens transexuais buscam visibilidade para novas gerações: entre os obstáculos que os homens trans encontram em seu percurso, o acesso à saúde continua a ser um dos mais dramáticos [Internet]. Correio Braziliense (Diários Associados) 2018 jun. 28 [citado em 2018 dez. 18]. Disponível em: https://www.correiobraziliense.com.br/app/noticia/brasil/2018/06/28/interna-brasil,691476/ homens-transexuais-buscam-visibilidade-para-novas-geracoes.shtml

39. Mendes A, Ferreira P. Transexuais já podem mudar nome em documentos nos cartórios de todo país [Internet]. O Globo (Globo S/A) 2018 jun. 29 [citado em 2018 dez. 18]. Disponível em: https://oglobo. globo.com/sociedade/transexuais-ja-podem-mudar-nome-em-documentos-nos-cartorios-de-todopais-22836060

40. Miguel LF. O jornalismo como sistema perito. Tempo Soc [Internet] 1999 [citado em 2018 dez. 18];11(1):197-208. Disponível em: https://bit.Iy/2QSMdvh

41. Clebicar T. Quem fala sobre transgêneros no jornal: análise das fontes mais acionadas nas notícias de 0 Globo em duas décadas (1997-2017). In: 18th IUAES World Congress; 2018 June 16-20. Florianópolis: UFSC, 2018.

42. Saffioti HIB. Contribuições feministas para o estudo da violência de gênero. Cad Pagu [Internet] 2001 [citado em 2018 dez. 18];16:115-36. Disponível em: https://bit.ly/2kVBtxI

43. Gomes R, Murta D, Facchini R, Meneghel SN. Gênero, direitos sexuais e suas implicações na saúde. Ciênc Saúde Coletiva [Internet]. 2018 jun. [citado em 2018 dez. 18];23(6):1997-2006. Disponível em: http://www.scielo.br/scielo.php?script=sci arttext\&pid=S1413-81232018000601997\&lng=en 
44. Resende F, Peres AC. Nós, as testemunhas: notas sobre um jornalismo de teor testemunhal. Dispositiva [Internet]. 2016 [citado em 2019 jan. 18];5(2):121-37. Disponível em: https://bit.ly/2wDekW5

45. França VRV, Souza FC, Lago FM, Lopes P. Testemunhos na mídia: o relato do sofrimento. Comunicação, mídia e consumo [Internet]. 2018 set-dez. [citado em 2019 jan. 18]; 44(15):120-39. Disponível em: http://revistacmc.espm.br/index.php/revistacmc/article/view/1580/pdf.

46. Gender in the global research landscape [Internet]. [place unknown]: Elsevier; 2017 [citado em 2019 maio 23]. Disponível em: https://bit.ly/2mGYruj

47. Fragale Filho R, Moreira RS, Sciammarella APO. Magistratura e gênero: um olhar sobre as mulheres nas cúpulas do judiciário brasileiro. E-cadernos CES [Internet]. 2015 [citado em 2019 maio 23]:24. Disponível em: http://journals.openedition.org/eces/1968

48. Leite TC. Sobre jornalistas e médicos: relações, contextos e mediações [dissertação na Internet]. Rio de Janeiro: Fundação Oswaldo Cruz; 2014 [citado em 2019 jan. 08]. Disponível em: https://www.arca. fiocruz.br/handle/icict/25316

49. Medeiros FNS, Ramalho M, Massarani L. A ciência na primeira página: análise das capas de três jornais brasileiros. Hist Cienc Saude-Manguinhos [Internet]. 2010 jun. [citado em 2019 jan. 08];17(2):439-54. Disponível em: http://www.scielo.br/scielo.php?script=sci_arttext\&pid=S0104-59702010000200010 